\title{
Ex ante impact assessment and seasonal climate forecasts: status and issues
}

\author{
P. K. Thornton* \\ International Livestock Research Institute (ILRI), PO Box 30709, Nairobi 00100, Kenya
}

\begin{abstract}
The field of ex ante impact assessment has been receiving increasing attention in recent years, due in part to the rapidly changing nature of funding for agricultural research and the shifts that have occurred in what is expected of the international agricultural research community. Ex ante studies are often carried out to provide information to assist in the allocation of scarce research resources to activities that are efficient in some way, or that best match donors' development objectives. In practice, impact assessment is often contentious and usually difficult. Despite this, a wide range of tools has been developed for ex ante impact assessment, and these are used routinely in many different areas. Here, various ex ante impact assessment methods are outlined that may be used to provide aggregated information at the scale of the region or society. Also discussed is how technological and policy changes associated with seasonal climate forecasts in developing countries can be assessed through a combination of these methods. Recent developments in quantitative modelling, and the availability of high-resolution regional and global data sets, could in the future contribute significantly to the identification of niches where seasonal climate forecasts could help vulnerable people cope with variability, with concomitant impacts on the alleviation of poverty.
\end{abstract}

KEY WORDS: Targeting · Innovation · Ex ante - Evaluation · Impact assessment · Climate forecast · Risk Resale or republication not permitted without written consent of the publisher

\section{INTRODUCTION}

The ability to predict climate fluctuations months in advance is improving to the point where there are good prospects for using such forecasts to modify the management of crops and livestock so as to ameliorate some of the negative impacts of climate variability in some environments (Mason 2001, Hansen 2002, O'Brien \& Vogel 2003). Seasonal climate forecasts are based on the interactions between ocean and atmosphere as manifested in sea surface temperatures, which can offer some predictability in terms of future temperatures and rainfall amounts (Ziervogel et al. 2005). Regional forecasts are largely dependent on El Niño-Southern Oscillation events (Mason et al. 1996).

If improved forecasting is to be harnessed effectively, however, various conditions will need to be met. Seasonal climate forecasts must address a real and perceived need, and they must have value (Hansen
2002). There are also clear needs for appropriate institutional structures that are adapted to manage such processes (Hudson \& Vogel 2003, O'Brien \& Vogel 2003). Ziervogel et al. (2005) note that the use of forecasts can be seen as an innovation, which is not widely adopted as yet in developing countries. If seasonal forecasts are treated as any other agricultural technology or innovation, albeit with some distinct characteristics, then there would seem to be some value in attempting to assess their likely adoption and value using the continually-evolving tools of ex ante impact assessment. Such analysis could help to identify major opportunities for their use, as well as identifying the critical barriers to their uptake.

There is a considerable literature on the value of forecast information to individual decision makers or groups of decision makers, using various approaches such as Bayesian decision analysis (Baquet et al. 1976) and dynamic programming (Sonka et al. 1987). Much 
of that work is summarised in Katz \& Murphy (1997). The focus of this paper, however, is the issue of the potential value of forecast information at the aggregate level, i.e. the potential costs and benefits to society of public resource investments in research, output delivery and policy formulation and implementation, in pursuit of governmental or societal objectives. The evaluation of climate forecast information for individual decision makers can then be linked directly to such broader ex ante impact assessment evaluations. Sometimes it may be possible to aggregate the value of forecast information to all decision makers to estimate its societal value, but this is likely to involve several difficulties. One difficulty is that insufficient information is usually available as to the objectives and attitudes of large numbers of decision makers; a second is that for an aggregated analysis, the analytical framework usually has to be broadened to include the potential impacts of specific decisions made by many individual decision makers on regional production levels and hence on commodity prices. Because of these difficulties, a more generalised approach to ex ante impact assessment is presented below, which may or may not involve the evaluation of climate forecast information for individual groups of decision makers using methods such as those described in Katz \& Murphy (1997), for example.

An overview of this approach is presented in the next section, with some examples of its use. The nature of seasonal climate forecasts means that there are distinct problems for assessing their impact, and these are outlined together with some possibilities for dealing with the challenges posed. The final section contains some suggestions for promoting better linkages between the methods of ex ante impact assessment and the general area of climate forecasts. These linkages will be crucial for identifying those situations in which climate forecasts can play a key role in helping resource-poor and vulnerable households deal with increasing variability and risk.

\section{EX ANTE IMPACT ASSESSMENT}

In the context of the present study, impact assessment is the evaluation of the effects of societal change in agricultural systems. In general, change may be brought about by indigenous innovation, research, such as a new technology or a new policy, or by other drivers such as population growth or market collapse (Thornton et al. 2003). The effects that may be assessed include changes in production and productivity, income, food security, social welfare, and the environment (Peterson \& Horton 1993), and may also be assessed at different scales, such as the farm, water- shed or nation. Depending on the purpose, impact assessments may have to take account of the ecological, economic and social subsystems operating at particular scales. Increasingly, it seems that impact assessments which study change that has already occurred (ex post) and, particularly, change that has yet to occur (ex ante), require mixtures of models and analytical tools to generate appropriate information concerning the effects of this change (Thornton \& Herrero 2001).

There are several reasons for the increased prominence that has been given to impact assessment in recent years, in particular the rapidly changing nature of funding for agricultural research, and the substantial shifts that have occurred in what is expected of the 'research for development' community on the part of the donors (Thornton et al. 2003). The reasons why people do ex ante impact assessment studies are clear: to help to identify those researchable issues that will, if resolved, lead to desirable outcomes, such as having widespread benefits for large numbers of poor people. Ex ante studies can help with the difficult decisionmaking in the allocation of limited resources. Another related role is the targeting of innovation, i.e. identifying what may work where. This targeting function is increasingly important, given the complexity, dynamism and heterogeneity of most farming systems in developing countries. As noted in the introduction (Section 1), this aggregate level of impact assessment contrasts with studies at the level of the individual decision maker concerning the value of forecast information for specific tactical and strategic decisions concerning farm and resource management.

A 'traditional' view of ex ante impact assessment is shown in Fig. 1 (adapted from Randolph et al. 2001). Resources are utilised (scientist years, operating costs, capital investment, etc.) to achieve some intended research output, with a given probability of success. If the intended research output can indeed be generated, a process of adaptive research may follow, or it may be that research outputs or products need to be customised to specific geographical areas, production systems, or sets of end-users. There may thus be some process of evaluation before the product or output is released. Eventually, the product or output is disseminated to end-users through formal or informal extension channels, with some associated costs. Adoption of the end-product is then often assumed to begin immediately at the end of the research project period, and then to follow a sigmoidal curve by which adoption starts very slowly, gradually accelerating, then decelerating until the adoption ceiling is reached. The 2 parameters that define the adoption period are (1) the time to maximum adoption (the adoption lag) and (2) the adoption ceiling or maximum level of adoption ( $A$ in Fig. 1). An estimate of the adoption ceiling is 


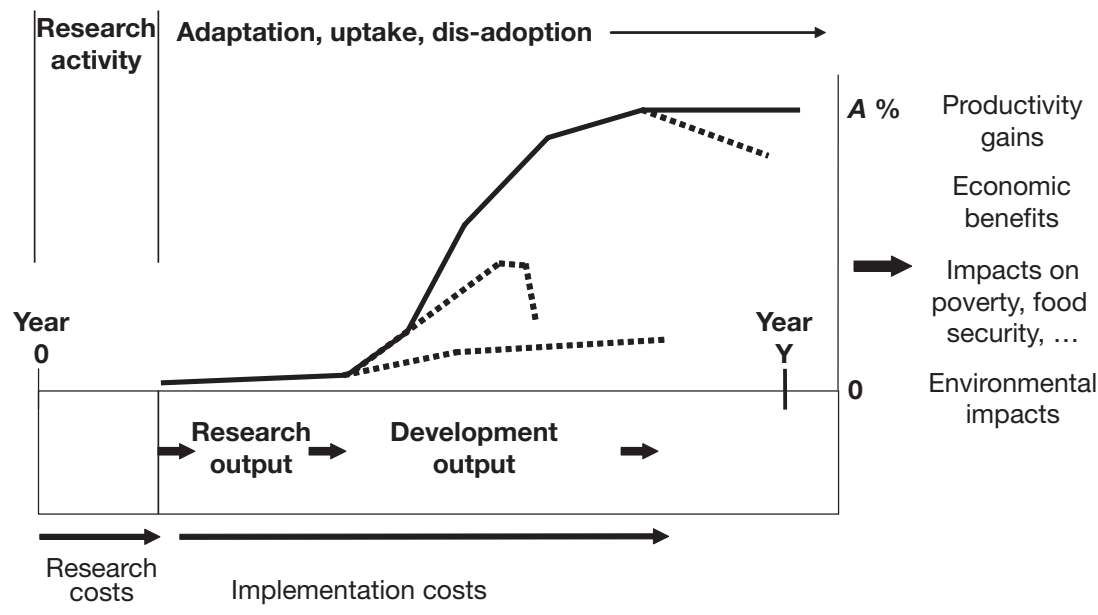

Fig. 1. A framework for ex ante impact assessment of innovation (after Randolph et al. 2001). Dotted curves: different rates and levels of adoption. A: adoption ceiling (percentage of decision makers that adopt)

based on 2 elements: the extent of the problem being addressed by the research, and the proportion of end users within that domain who are likely to adopt the end product based on the research. To carry out an ex ante assessment, the analyst then needs to estimate the various parameters associated with the research, to arrive at a value (or a set of values) that characterises the research proposed. If an entire portfolio of candidate research activities are valued in this way, this can help inform decisions as to what research should be undertaken, and where (see Randolph et al. 2001 for an example).

The view that upstream research produces outputs that are then adapted and passed on to extension services, which then disseminate the innovation to farmers, has been the normal view in agricultural research and development for a long time. This is not surprising; the Green Revolution is often seen as a triumph of this 'transfer of technology' approach (Douthwaite et al. 2004). More recently, different approaches to the innovation process have been developed to deal with the increasing complexity, heterogeneity and dynamism of agricultural systems. An example of a new approach to the innovation process is that associated with integrated natural resource management (INRM). Such research seeks to deal with the complexity of systems by redirecting the objectives of research toward enhancing adaptive capacity, by incorporating more participatory approaches, by embracing key principles such as multi-scale analysis and intervention, and by the use of a variety of tools for systems analysis, information management, and impact assessment (Sayer \& Campbell 2001). For such research, the innovation process may be much more complicated than the linear process shown in Fig. 1, but the general framework is still useful for thinking about different types of uptake curve applicable in different situations (the dotted curves in Fig. 1). Uptake may be long and slow, there may be partial uptake with subsequent widespread dis-adoption, and uptake may scarcely occur at all. But however innovation is viewed as occurring, resources are still needed for the process, there are costs involved, and the impacts of uptake can be measured, although these may go beyond productivity impacts to include impacts on vulnerability, risk, and food security, for example. It is also within this framework that key feedbacks may need to be incorporated. For instance, in a region, if production of a commodity increases, what are the subsequent impacts on prices, and how may these price changes affect later adopters? Will it be only the early adopters of production technology who benefit, so that producers in general may not gain a great deal, even though societal gains (through cheaper food, for example) may be substantial?

To give an idea of the breadth of tools and methods that are available for ex ante impact assessment, Table 1 lists 18 such methods, drawn from Alston et al. (1995) and reviews in Thornton et al. (2000, 2003). For each, there is a brief description, a few of the major advantages and disadvantages, and its suitability to address 3 major parts of the research innovation process (however it is viewed): (1) the research process itself, involving the identification of appropriate researchable issues, the time, skills and resources required, the partnerships needed, and the probability of producing the designed output ${ }_{i}(2)$ the uptake process, involving adoption and adaptation by farmers, and the policy, information and infrastructural support that may be required to buttress this process; and (3) the evaluation of impacts relating to production and productivity, the environment, poverty alleviation, etc. An approximate (and subjective) suitability score is given to each method in relation to these 3 stages, in terms of whether the method is useful for addressing the questions that arise at each stage. For example, expert opinion or peer review (number 3 in Table 1) involving panels of experts may be highly effective in identifying feasible researchable issues in an area, but this is not an effective method for dealing with uptake; issues related to uptake are much more effectively addressed using household- and community-level studies. Two major points are apparent from Table 1. First, no single method is highly suitable for dealing with the issues associated with all 3 processes; for a comprehensive 


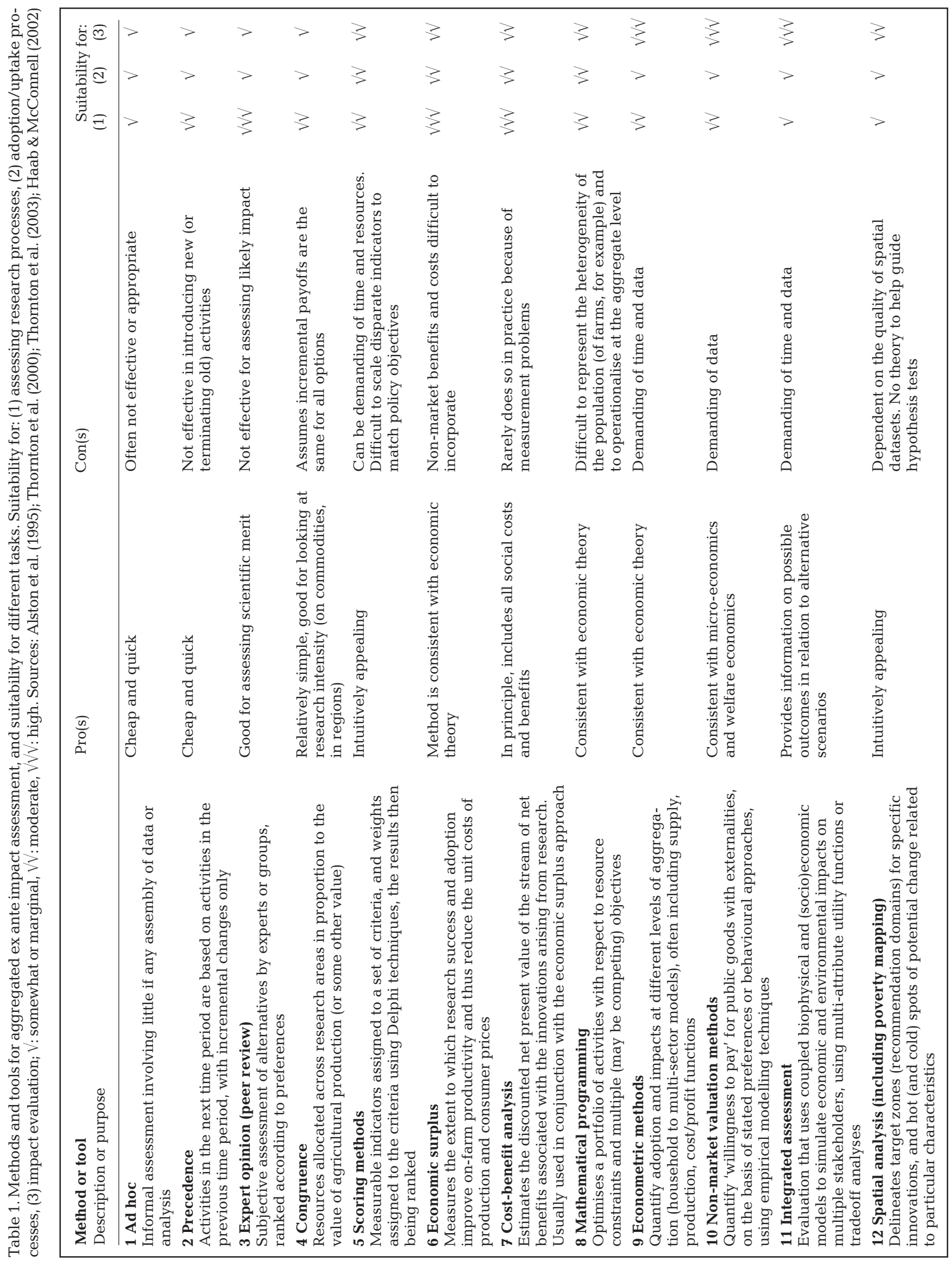




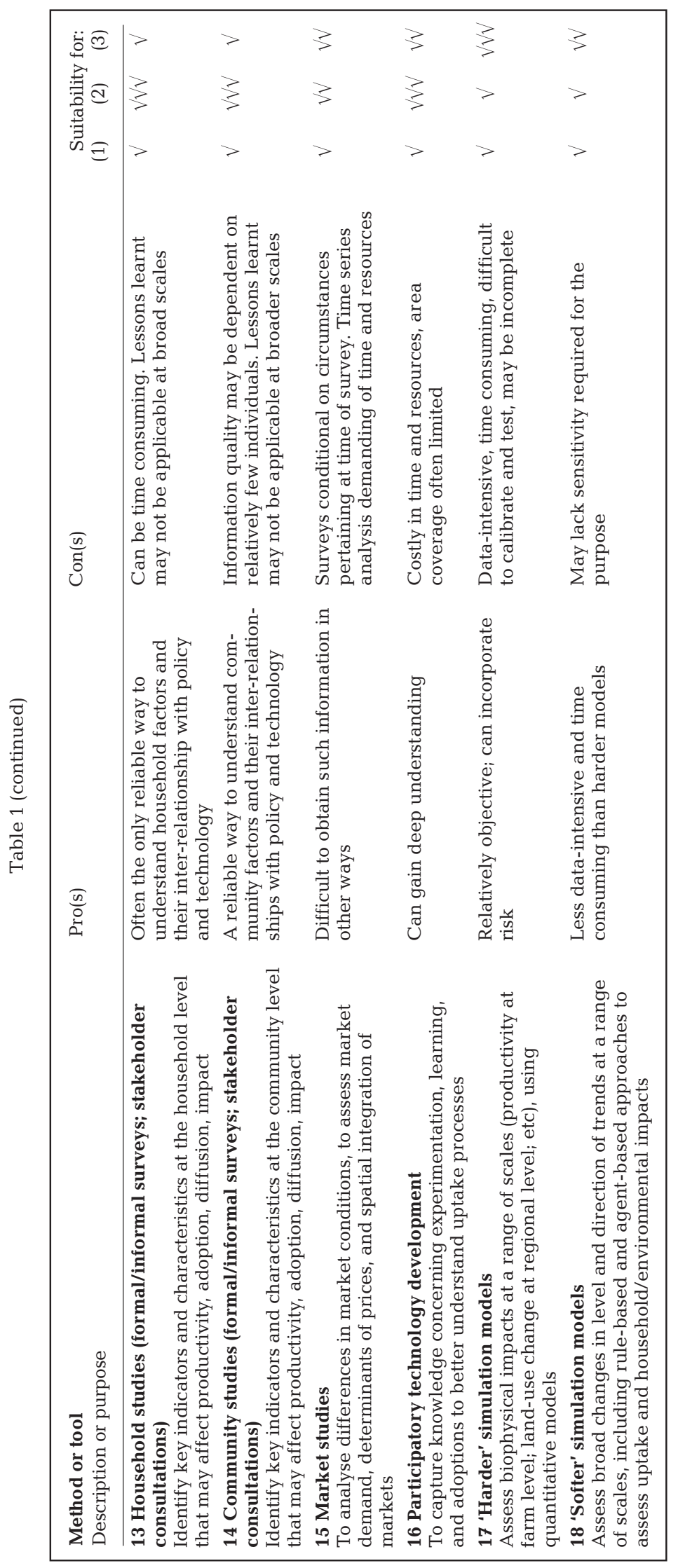

assessment, a mixture of methods will be required. Second, in any choice of methods and tools, trade-offs will always have to be made between comprehensiveness, the skills needed, and the time and resources available.

\section{QUESTIONS INVOLVED IN ASSESSING IMPACTS}

There are various questions that have to be asked in any ex ante impact assessment. One set of questions has to do with defining research or policy formulation activities that are feasible within the constraints of time and resources that apply, that have an acceptable chance of success in the sense of producing useful outputs, and that together make up an appropriate portfolio of activities for the organisation or partners undertaking the activities in question. Beyond this, with particular research products or outputs in mind, there are essentially 4 inter-related (and often overlapping) questions that have to be addressed: (1) Where are the impacts likely to occur? (2) Who will the impacts affect? (3) Which impacts will have an effect? (4) What is the value of these impacts? These questions are considered in more detail below, together with the use of some of the methods listed in Table 1.

\subsection{Impact where?}

The first question requires the analyst to identify the potential area of impact associated with the innovation. In the past, the potential area has often been defined in geographical or agroecological terms, and it is assumed that the innovation is relevant within such an area. Allied to this has been the identification of 'benchmark' sites for carrying out key research, on the basis that if a certain biophysical response is obtained, and if the benchmark site can be taken as being representative of a much broader environment, then the response may be assumed to apply throughout that environment or domain. The notion of 'recommendation domains' for agricultural innovation, developed or tested at benchmark sites that are representative of larger areas, is a key concept for much recent agricultural research (see, for example, Douthwaite et al. 2001). Unfortunately, biophysical factors, while important, are not the only reasons for the applicability, uptake or adoption of innovation. 
Socio-economic and politico-cultural factors may be of equal or greater importance, but it is not easy to define meaningful demand domains on the basis of socioeconomic and politico-cultural variables.

To answer the question, 'Where will impacts occur?' spatial databases and Geographic Information Systembased (GIS-based) analysis, which may range from the very simple to the highly complex (Method 12, Table 1), can be used. There are many examples of such work. For example, Kristjanson et al. (2002) carried out survey work that found, for dual-purpose (i.e. as a nitrogen-fixing food crop and as animal fodder) cowpeas in northern Nigeria, that the intensity of adoption (the proportion of total cowpea area planted to improved dual-purpose varieties) was strongly influenced by the density of livestock, human population density, and the degree of market access. In mapping out the potential adoption zone of dual-purpose cowpeas in the region, data layers of livestock and human population densities and market accessibility indicators were overlaid to identify zones of differing adoption potential, with differing adoption lags and ceiling adoption levels.

In recent years, various institutions, including the international agricultural research centres, the FAO, the World Bank, and many others, have assembled considerable holdings of spatial data. These GIS databases are being combined with models to carry out relatively sophisticated, broad-brush analyses to identify target populations characterised in particular ways. Such studies have made use of a range of spatial data, such as human population and livestock densities, cropping areas, soil maps and soil property data, land slope and elevation, land use and land cover, road and transport infrastructure, protected areas and wetlands, climate and weather data, length of growing period, distribution of livestock disease vectors, large mammal biodiversity, and agricultural systems. Through time, global datasets are becoming more widely available, and are of increasingly high resolution. Recent examples include new $1 \mathrm{~km}$ resolution climate grids for the globe (Hijmans et al. 2005), new livestock density data for the major domesticated species (Wint 2005), and global human population coverages that are able to distinguish in detail between rural and urban populations (CIESIN 2004).

\subsection{Impact on whom?}

The first question (Where will impacts occur?) is the initial step in identifying potential target populations. The next question, 'Who will the impacts affect?' involves identifying key characteristics of target populations. These may be to do with the type of agricul- tural system that is operated, proximity to particular types of natural resource or urban centres, species of livestock raised, or particular household characteristics (female-headed for instance).

Given the widespread focus of development organisations on poverty alleviation, one characteristic of target populations that is becoming increasingly important in impact assessment studies is their poverty status. Techniques for high-resolution (i.e. to 3rd, 4th or 5th sub-national administrative levels within a country) poverty mapping, such as small-area estimation, can be used to derive estimates of the percentage of the population living below the poverty line within small geographic areas containing a few hundred households (Hentschel et al. 2000, Elbers et al. 2001). Apart from traditional household-level factors, spatial factors are likely to be crucial in understanding levels of poverty at the broader landscape or community level. However, understanding why some households are poor and others not so poor in particular places is complex, as might be expected; recent studies — such as by Kristjanson et al. (2004) - have shown (using a combination of Methods 12, 13 and 14 in Table 1) that while there are spatial determinants, seemingly random but highly important events in the lives of individual families are also critical in determining whether families fall into, or are lifted out of, poverty.

\subsection{Impact types?}

The third question, 'Which impacts will have an effect?' involves what may be quite sophisticated understanding of the agricultural system, possibly at several levels in the hierarchy of this system. Many ex ante impact assessments involve some sort of typology or classification of households within the target domain, and household-level impacts are estimated using secondary information or models of some sort, the results of which are then aggregated to provide estimates of impact at the regional level. An example is provided by the study of Thorne et al. (2003), which describes an ex ante impact assessment study to generate information to help guide future research activities in east and southern Africa concerning the maize crop in the mixed systems of the region. From characterisation studies carried out in countries in the region, 4 systems were defined in terms of human population density and maize cropping density, and subsequently mapped for the region. Various alternative maize-related management options were assessed, such as improved management of green maize stover for feed use and improved feeding systems incorporating dry maize stover. Productivity impacts of these system changes (in terms of meat, milk, maize, and changes in soil fertility status) were assessed using crop 
and livestock simulation models. The household-level impacts by system within the various countries in which the interventions were judged to be relevant were then aggregated, using the GIS data layers derived in the characterisation stage. Each intervention-by-system combination was then assessed in relation to the potential impacts that could arise as a result of resource expenditures on research and extension to develop and disseminate the particular intervention. There were several results of this analysis; for example, improved feeding systems offer substantial potential for smallholders, particularly in the more intensive systems, and promoting the use of intercropping in the more extensive systems where this is not already practised also offers substantial net benefits. This study made use of Methods 6, 12, 13 and 17 in Table 1.

This process of clustering the population of households (or whatever the unit of analysis may be), defining a representative household for each cluster, estimating impact on each representative household, and then multiplying up the impacts from the representative household to the entire cluster, is a common way of estimating productivity impacts at aggregated level. It is sometimes possible to evaluate direct economic and environmental impacts in this way. Other impacts may be more difficult to evaluate, either because their effects may be indirect or because these effects may be very difficult to quantify. For example, what may the impacts of innovation be on issues such as household vulnerability and adaptive capacity? Again, if a productivity-enhancing innovation is widely taken up in a region, so that regional production increases greatly, what is likely to happen to commodity prices through time, and how may this affect both producers and consumers?

Such impacts that are deemed to be important but that are more difficult to quantify directly can be evaluated using some kind of scoring system. For example, in an ex ante impact assessment of the entire research portfolio of an institute, Randolph et al. (2001) identified capacity building as a key criterion. To assign a score for this criterion to each candidate research activity, a decision was made as to how research activities and outputs could have an impact on capacity building, in terms of likely strengthening of national human resources and national institutions for research, the likely impacts of research tools adapted to national research needs, and impacts of human resources and local institutions for development. Each of 5 criteria was scored from 0 (no impact) to 2 (high impact), giving an index from 0 to 10 , and with this simple scheme it was possible to rank current and future research activities in terms of their capacity-building potential. This is an example of a combination of Methods 5 and 6 (Table 1).

\subsection{Impact value}

In the framework of Fig. 1, various methods can be used to value impacts. These include scoring methods, cost-benefit analysis, econometric models, non-market valuation methods to evaluate social, environmental and health impacts (see e.g. Haab \& McConnell 2002), integrated assessment methods to evaluate economic and environmental impacts on multiple groups of stakeholders whose objectives may differ considerably, hard and soft simulation models, and combinations of these (Methods 5, 7, 9, 10, 11, 17 and 18, Table 1).

A common method for valuing impacts is economic surplus modelling (Method 6, Table 1). This involves the valuation of the benefits of the aggregated impacts and the total costs of the associated research and extension activities. In the economic surplus model (for detailed descriptions, see Alston et al. 1995 and Kristjanson et al. 1999), adoption of a new technology is assumed to shift the supply curve of the product (such as maize or meat), resulting in a new equilibrium price and quantity of the product marketed. Gross annual research benefits are calculated as the total increase in economic welfare (change in total surplus) and comprise both the changes in producer and consumer surplus resulting from the shift in supply. Consumers are better off because they consume more at a lower price. Producers may also be better off, because increased supply lowers their per unit costs of production; although they are receiving a lower price for their product, they may be selling more and thus further increasing their benefits (but in some circumstances producers may be worse off). Many impact assessments have used relatively simple models of a closed economy (assuming that there is little or no international trade in the commodities concerned), and linear supply and demand curves with parallel shifts. Considerable extension of the simple case is possible (Alston et al. 1995), although the data demands, even for the simple model, can become burdensome. There are, however, various software packages that can be used to carry out economic surplus modelling. These include a relatively simple spreadsheet-based programme by Mills (1998), and DREAM (Dynamic Research EvaluAtion for Management), which can simulate a range of market, technology-adoption, research-spillover, and trade-policy scenarios based on a flexible, multi-market, partial equilibrium model (IFPRI 2005).

\section{EX ANTE IMPACT ASSESSMENT AND CLIMATE FORECASTING}

There are various characteristics of climate forecasting that make ex ante impact assessment challenging. Three characteristics are considered here: (1) the prob- 
abilistic nature of forecasts and the impacts they may have; (2) the need for forecasts to be assessed in a dynamic framework; and (3) the institutional and policy prerequisites that are needed to make forecasts a viable option for marginalised and resource-poor people. In what follows, it is assumed that a real and perceived need exists, and that appropriate management options do indeed exist, so that some difference can be made to the livelihoods of those who use forecasts - 2 of Hansen's (2002) 'prerequisites to beneficial forecast use'.

\subsection{Use of climate forecasts and the nature of their impacts}

Ziervogel et al. (2005) note that the level of forecast use will generally depend on a host of factors, including the skill of the forecast and the credibility of the source. Forecast skill relates to the degree of correspondence between forecast and observation. Credibility relates to various factors such as past skill, forecast reputation, and the degree to which forecasts fit in with or contradict local beliefs about the climate (Ziervogel et al. 2005). In terms of the framework of Fig. 1, this complicated situation concerning likely levels of use of forecasts makes it difficult to estimate uptake rates.

Quite as difficult is the issue of measuring climate forecast impacts. At some stage in the analysis, these may need to be assessed at the level of the individual decision maker and then aggregated. A major issue with climate forecast impacts is that while there may be impacts on production levels of crops or livestock over the long term as a result of their use, there are also likely to be impacts on risk. This implies that some sort of risk framework has to be used to assess forecast impacts; without it, the picture is likely to be very distorted. There are various risk frameworks that allow the analyst to assess impacts of changes in risk, such as utility maximisation within a Bayesian framework (Katz \& Murphy 1997). However, aggregating personal risk attitudes is not straightforward, unless some assumptions are made as to the likely distribution among the population of risk aversion coefficients, for example.

A further problem is that in certain circumstances, forecast information may have little direct economic value in terms of modifying management decisions. In a study that looked at the use of long-term seasonal climate forecasts in Northwest Province, South Africa, Hudson (2002) found little evidence that communal farmers in the area would modify their livestock management practices in any way as a result of forecast information associated with El Niño-Southern Os- cillation events. However, forecasts may have cultural value to decision makers in terms of optimal management for asset accumulation, which is the major objective of owning livestock for these communal farmers (Hudson 2002). For commercial farmers in the same region, on the other hand, long-term average annual income could be increased substantially through utilizing forecasts to de-stock at particular times, but at the cost of increased year-to-year variability in farm income (Thornton et al. 2004).

\subsection{The need to assess impacts across time and space}

The need to assess impacts across time and space could be seen as a general requirement for all ex ante impact assessments, but within the framework of Fig. 1 it is seldom done. If innovation is taken up in a region by relatively large numbers of people, then impacts on commodity prices will have to be taken into account, as they may be considerable. This is particularly true in the case of forecast use. In the example of Northwest Province referred to above, the prices received by communal farmers for their livestock in drought years decreased dramatically, often by $50 \%$ or more compared with a normal-rainfall year (Hudson 2002). In situations where prices are highly volatile and sensitive to environmental conditions, estimates of forecast value may themselves be highly sensitive to key variables such as prices.

Impact assessment may thus need to make use of some sort of agricultural sector model that generates quantities and prices in response to changes in conditions. The economic surplus framework does this, but generally in a static framework - the change to a new price equilibrium is assumed to occur instantaneously, for example. It may be very important to capture adequately the dynamics of the uptake of innovation in a region. In such cases, there are other options, such as using a global partial equilibrium model like IMPACT (International Model for Policy Analysis of Agricultural Commodities and Trade, see Rosegrant et al. 2001, for example), but at the cost of increased data needs (Method 9, Table 1). In practical terms, some fallback on the use of historical prices and price analysis may have to be made. Without this, the estimated impacts may be seriously distorted.

\subsection{Assessing what is required of the institutional and policy environment}

All writers on the use of climate forecasts note the importance of an enabling institutional and policy environment, if climate forecasts are to be used for the 
benefit of society. Given that this is well recognised, it makes little sense to ignore it in an ex ante impact assessment, although identifying the necessary institutional and policy support in a region, and attributing realistic costs to it, are likely to be very difficult. Systematic efforts to understand the interactions between institutions and the patterns of information flow and cooperation between the institutions responsible for providing forecasts to farmers are very useful in identifying strong and weak parts of the process (Kirshen \& Flitcroft 2000, Hansen 2002), but such studies are not common. As noted above, for most ex ante impact assessments, time and resources are likely to be severely constraining.

In such cases, scoring methods may have to be used, that allow the analyst or experts in the area to assign numbers that represent the strength of association between, for example, the effort and resources needed to set up and maintain institutional linkages and their likely effectiveness in getting relevant information to farmers. That such qualitative information can (and should) be combined with what may be much more quantitative information (on prices, or on production impacts, for example), is often a key conceptual hurdle in applying impact assessment methods. Scientists from the more upstream or 'harder' end of the spectrum may have a real aversion to scoring and ranking methods, and this has to be overcome if best use is to be made of scientists' expertise as a critical input to the impact assessment process.

\section{ADVANCING THE AGENDA}

To make advances in the field of climate-forecast impact assessments, it helps to identify areas that need attention. One such area relates to targeting. Solid baseline information is required to understand who the potential clients are, what characterises them, how are they linked to relevant and appropriate institutions, and how information flows between the major actors in the system, and specialised survey data may be required in particular circumstances. As noted above, spatial data sets for region and continent are increasingly available at higher resolution, but there are still other factors that will require increased understanding if the targeting of forecast information is to be effective.

A second area for attention relates to the application of new tools, or tools from other disciplines, to assist in the evaluation of impacts, some of which are peculiar to the nature of climate forecasts. These would include the specification of comprehensive behavioural frameworks that go beyond current notions of risk theory, so that impacts on food security, reduction of vulnerability, and increases in household adaptive capacity can be addressed. These impacts are much harder to value satisfactorily than more traditional production or income increases, but without valuing these appropriately in some way, much of the value of forecast information to many households may be seriously underestimated. Developments in both hard and soft models may help in evaluating impacts. One area that holds out some potential is the agent-based approach, a relatively recent and rapidly developing research area. This approach involves the development and use of models of interacting collections of agents, and emphasizes dynamics, processes, and patterns of relationships among agents. Such models are characterized by the existence of many agents who interact with each other with little or no central direction. The emergent properties of an agent-based model (ABM) are then the result of 'bottom-up' processes, rather than 'topdown' direction (Axelrod 1997; Bonabeau 2002). There are now many examples of ABMs in several general areas, including a recent example for assessing impacts of climate forecasting in Lesotho (Ziervogel et al. 2005). The fact that emergent phenomena can arise from agent-based models is one of their most appealing features, conceptually. On the other hand, for models to be most useful, they must be structurally appropriate, i.e. they need to correspond to the mechanisms operating in the real system under study (Couclelis 2002). Given the complexity of human decision making and of the ecosystems within which humans seek their livelihoods, adequate understanding of these mechanisms may be difficult to come by. Consequently, verification of agent-based models can present some difficulties. This involves assessing an ABM in terms of its ability to represent current situations in particular case-study areas, and then using the model for scenario analysis to assess likely impacts of change-this is doable, at least. Whether enough is known about household-level decision-making processes to render ABMs truly powerful in assessing the impacts of change remains to be seen, but the prospects are certainly intriguing.

Another set of tools that may offer scope for resolving some of the difficult problems associated with evaluating impacts is in the field of systems dynamics. Systems dynamics encompasses a modelling method that facilitates the development of formal computer simulations of complex systems and their use to design more effective technologies and policies (Nicholson 2005). Some would argue that the method is more than the application of certain mathematical methods. Rather, it involves the application of mathematical techniques with a particular perspective, particularly to dynamic complexity, feedback, problem orientation, and the analysis of general dynamic tendencies. Systems dynamics models have been applied to a wide 
range of engineering problems, and to some extent in agricultural development (e.g. Kassa et al. 2002), but there would seem to be as yet untapped possibilities of developing and applying systems dynamics models to climate forecasting and livelihood issues in a number of ways. Nicholson (2005) also notes the possibility of group model-building activities as a relatively quick way of tapping into considerable knowledge of how systems work, and the possibility of formalising this expertise in effective ways - again, something potentially valuable with respect to time- and resourceconstrained impact assessment work.

A third area of activity in the future that should help to improve the effectiveness of impact assessments of climate forecasts is the development of hybrid approaches that combine the quantitative with the qualitative, the top-down with the bottom-up, and the socio-economic with the biophysical. It is clear from Table 1 that different approaches bring different strengths to impact assessment activities, and there is a need to develop innovative, multi-method approaches that will allow all the major impacts arising from the use of climate forecasts to be assessed in a comprehensive fashion.

On-going developments in quantitative modelling, and the availability of high-resolution regional and global data sets, including poverty maps, are likely in the future to contribute significantly to the utility of impact assessments, including those associated with climate forecast information. The dynamism, complexity and heterogeneity of agricultural systems in many parts of the developing world all combine to suggest that targeting will become increasingly important in the future. Ex ante impact assessment will continue to play an increasing role in helping to target research for development activities, including identifying niches where seasonal climate forecasts can help vulnerable people cope with variability, resulting in concomitant impacts on the alleviation of poverty.

Acknowledgements. Without implicating them in any way, I am very grateful to P. Kristjanson, M. Herrero and C. Nicholson for various inputs. The comments and suggestions of anonymous referees on an earlier draft of the paper are also gratefully acknowledged.

\section{LITERATURE CITED}

Alston JM, Norton GW, Pardey PG (1995) Science under scarcity. Cornell University Press, Ithaca, NY

Axelrod R (1997) Advancing the art of simulation in the social sciences. In: Conte R, Hegselmann R, Terna P (eds) Simulating social phenomena. Springer-Verlag, Berlin, p 21-44

Baquet AE, Halter AN, Conklin FS (1976) The value of frost forecasting: a Bayesian appraisal. Am J Agric Econ 58:511-520
Bonabeau E (2002) Agent-based modeling: methods and techniques for simulating human systems. Proc Natl Acad Sci USA 99:72807287

CIESIN (Center for International Earth Science Information Network) (2004) Gridded Population of the world (GPW) III beta version. Available at: http://beta.sedac.ciesin. columbia.edu/gpw/download.html

Couclelis H (2002) Why I no longer work with agents: a challenge for ABMs of human-environment interactions. Section 1.3 in: Parker DC, Berger T, Manson WM (eds) Agentbased models of land-use and land-cover change. LUCC Report Series no. 6, LUCC International Projects Office, Louvain-la-Neuve. Available at: www.geo.ucl.ac.be/LUCC

Douthwaite B, Weise S, Gockowski J, Keatinge D, Manyong V, Baker D (2001) IITA's benchmark area approach: putting INRM into practice. Paper presented at the Integrated Natural Resource Management Workshop, Centro International de agricultura Tropical, Cali, 28 to $31 \mathrm{Au}-$ gust. Available at: www.ciat.cgiar.org/inrm/workshop2001/ docs/titles/4-1AAbstractBDouthwaite.pdf

Douthwaite B, de Haan N, Manyong VM, Keatinge JDH (2004) Blending 'hard' and 'soft' science: the 'follow-thetechnology' approach to catalyzing and evaluating technology change. In: Campbell BM, Sayer JA (eds) Resource management: linking productivity, the environment and development. CABI Publishing, Wallingford, p 15-32

Elbers C, Lanjouw J, Lanjouw P (2001) Welfare in villages and towns: micro-measurement of poverty and inequality. Development Economics Research Group (DECRG), The World Bank, Washington, DC (mimeo)

Haab TC, McConnell KE (2002) Valuing environmental and natural resources. Edward Elgar, Cheltenham

Hansen JW (2002) Realising the potential benefits of climate prediction to agriculture: issues, approaches, challenges. Agric Syst 74:309-330

Hentschel J, Lanjouw J, Lanjouw P, Poggi J (2000) Combining census and survey data to trace the spatial dimensions of poverty: a case study of Ecuador. World Bank Econ Rev 14 (1):147-165

Hijmans RJ, Cameron S, Parra J (2005) WorldClim climate surfaces. Available at: www.worldclim.org

Hudson JW (2002) Response to climate variability in the livestock sector in the North-West Province, South Africa. MA thesis, Colorado State University, Fort Collins

Hudson J, Vogel C (2003) The use of seasonal forecasts by livestock farmers in South Africa. In: O'Brien K, Vogel C (eds) Coping with climate variability: the use of seasonal climate forecasts in Southern Africa. Ashgate Press, Aldershot, p 75-96

IFPRI (International Food Policy Research Institute) (2005) DREAM version 3. Software online at www.ifpri.org/ dream.htm

Kassa H, Blake RW, Nicholson CF (2002) The crop-livestock subsystem of livelihood dynamics in the Harar Highlands of Ethiopia. Paper presented at the International Conference 'Responding to the increasing global demand for animal products', Merida, Mexico, November 12-15. British Society of Animal Science, Penicuik, p 74-75

Katz RW, Murphy AH (eds) (1997) Economic value of weather and climate forecasts. Cambridge University Press, Cambridge

Kirshen P, Flitcroft I (2000) Use of seasonal precipitation forecasting to improve agricultural production in the SudanoSahel: an institutional analysis of Burkina Faso. Nat Resour Forum 24:185-195

Kristjanson P, Swallow BM, Rowlands GJ, Kruska RL, de Leeuw PN (1999) Measuring the potential benefits of con- 
trolling African animal trypanosomosis and the returns to research. Agric Syst 59:79-98

Kristjanson P, Tarawali S, Okike I, Singh BB, Thornton PK, Manyong VM, Kruska RL, Hoogenboom G (2002) Genetically improved dual-purpose cowpea: assessment of adoption and impact in the dry savannah of West Africa. International Livestock Research Institute Impact Assessment Series Number 9. ILRI, Nairobi

Kristjanson P, Krishna A, Radeny M, Nindo W (2004) Pathways out of poverty in eastern Kenya and the role of livestock. Pro-Poor Livestock Policy Initiative, Work Pap 14, FAO Animal Production and Health Division, Rome

Mason S (2001) El Niño, climate change, and Southern African climate. Environmetrics 12:327-345

Mason SJ, Joubert AM, Cosijn C, Cromp SJ (1996) Review of seasonal forecasting techniques and their applicability to southern Africa. Water SA 22:203-209

Mills B (ed) (1998) Agricultural research priority setting: information investments for improved use of resources. ISNAR (International Service for National Agricultural Research), The Hague

Nicholson CF (2005) Some thoughts on the use of system dynamics modeling for assessment of the evolution of agriculture-based livelihood systems. Department of Applied Economics and Management, Cornell University, Ithaca, NY (mimeo)

O'Brien K, Vogel C (2003) A future for forecasts? In: O'Brien $\mathrm{K}$, Vogel C (eds), Coping with climate variability: the use of seasonal climate forecasts in Southern Africa. Ashgate Press, Aldershot, p 197-211

Peterson W, Horton D (1993) Impact assessment. In: Horton D, Ballantyne P, Peterson W, Uribe B, Gapasin D, Sheridan K (eds) Monitoring and evaluating agricultural research. CAB International, Wallingford, p 100-107

Randolph TF, Kristjanson PM, Omamo WS, Odero AN, Thornton PK, Reid RS, Robinson T, Ryan JG (2001) A framework for priority setting in international livestock research. Res Eval 10(3):142-160

Rosegrant MW, Paisner MS, Meijer S, Witcover J (2001) Global food projections to 2020: emerging trends and

Submitted: May 12, 2005; Accepted: January 4, 2006 alternative futures. 2020 Vision Food Policy Report, International Food Policy Research Institute, Washington, DC

Sayer JA, Campbell BM (2001) Research to integrate productivity enhancement, environmental protection, and human development. Conserv Ecol 5(2):32. Available at: www. ecologyandsociety.org/vol5/iss2/art32/

Sonka ST, Mjelde JW, Lamb PJ, Hollinger SE, Dixon BL (1987) Valuing climate forecast information. J Clim Appl Meteorol 26:1080-1091

Thorne PJ, Thornton PK, Kruska RL, Reynolds L, Rutherford AS, Waddington SR, Odero AN (2003) The maize crop as food, fodder and fertiliser in intensifying crop and livestock systems in East and Southern Africa: an ex ante impact assessment of technology interventions to improve smallholder welfare. International Livestock Research Institute Impact Assessment Series Number 11. ILRI, Nairobi

Thornton PK, Herrero M (2001) Integrated crop-livestock simulation models for scenario analysis and impact assessment. Agric Syst 70:581-602

Thornton PK, Randolph TF, Kristjanson PM, Omamo WS, Odero AN, Ryan JG (2000) Assessment of priorities to 2010 for the poor and the environment. International Livestock Research Institute Impact Assessment Series Number 6. ILRI, Nairobi

Thornton PK, Kristjanson PM, Thorne PJ (2003) Measuring the potential impacts of improved food-feed crops: methods for ex ante assessment. Field Crops Res 84:199-212

Thornton PK, Fawcett RH, Galvin KA, Boone RB, Hudson JW, Vogel CH (2004) Evaluating management options that use climate forecasts: modelling livestock production systems in the semi-arid zone of South Africa. Clim Res 26:33-42

Wint W (2005) Working files produced for the Food and Agriculture Organisation Animal Product Division division by Environmental Research Group Oxford. Available at: http://ergodd.zoo.ox.ac.uk/

Ziervogel G, Bithell M, Washington R, Downing T (2005) Agent-based social simulation: a method for assessing the impact of seasonal climate forecast applications among smallholder farmers. Agric Syst 83:1-26

Proofs received from author(s): November 17, 2006 